\title{
Sustainable development of new technologies for clustering human capital (cenological approach)
}

\author{
Alexandra Voronina ${ }^{1, *}$, Alexander Kuzminov ${ }^{2}$, Alexander Okhotnikov ${ }^{1}$, and Oksana \\ Sorokina ${ }^{1}$ \\ ${ }^{1}$ Rostov State Transport University, 344038, 2, Rostovskogo Strelkovogo Polka Narodnogo \\ Opolcheniya Sq., Rostov-on-Don, Russia \\ ${ }^{2}$ Rostov State University of Economics, 344002, B. Sadovaya str. 69, Rostov-on-Don, Russia
}

\begin{abstract}
The article examines the stratification of human capital as a categorical unit of a research in the digital information space. The necessity of cognition of the properties and living conditions of generations arising from the nature of functioning in new categories of social and economic interaction is revealed. The authors substantiate the thesis that the study of the complex structure of human capital, prospects and dynamics of interaction is one of the most urgent tasks in the information space. Scientific research in this area can provide an invaluable contribution to improving the system of public administration and management of human capital in modern Russia. The article proposes the use of a cenological approach to the study and assessment of human capital as a theoretical and methodological basis for modeling and managing social systems. The goal is to develop approaches to the creation of a targeted structure of human capital, allowing the construction of a key social image in the information and digital environment.
\end{abstract}

\section{Introduction}

The relevance of the problem is due to the contradictions in the existing methodology for studying human capital in the information-digital space. They have arisen as a result of the transformation of socio-economic ties and relations, institutional transformations, the digitalization of social space in recent decades and the inevitable complication of socioeconomic systems.

The existing methodology for analyzing complex social systems, including the structure of human capital, is limited by fragmentation, incompleteness and lack of a basic conceptual foundation in the research process itself. Many analytical models do not allow to identify accurately and fully the existing social groups in the digital environment, just as they cannot project the formation of new groups. All this is reflected in superficial theorization and hinders the development of methodology and turns out to be useless at the level of practical management of generations in the information space.

\footnotetext{
*Corresponding author: caas@mail.ru
} 
The available research models do not answer a number of questions related to the nature of the formation and dynamics of the structure of complex socio-economic systems (generations) and do not provide the possibility of interdisciplinary synthesis $[1,2]$. This is necessary to expand the methodological analytical field itself. The need for interdisciplinary research, adequate to the changing socio-economic realities, is due to the limitations of traditional approaches, insufficiently revealed on their basis the complex structure of the object, often - a weak level of interpretation of the phenomena under study. For sociosystemic studies, it becomes extremely important to acquire unified general methodological approaches based on interdisciplinary analysis using cybernetic methods and synthesis with a developed cenological theory.

Some scholars propose to use epistemological integration in their studies [3]; others substantiate micro and macroeconomic influence from a system-wide standpoint [4]. For the formation of research scenarios, it is advisable to use a number of fundamental works that are devoted to the effectiveness of solving complexity [8], the method of grouped quantile IV [9] for understanding economic reality and analysis of the stochastic impact of endogenous factors on socio-economic phenomena [10].

\section{Research objectives and foundations}

The purpose of this study is to develop an approach to understanding the processes of formation of the structure of generations in the information space based on the substantive provisions of the cenoses theory. The approach will increase the effectiveness of public administration aimed at increasing the efficiency of the use of resources for the formation of social subsystems with characteristics corresponding to the new society, the goals of the state, the region, industries and enterprises, as well as the individual.

To achieve this goal, it is necessary to solve the following tasks.

1. To give a theoretical basis for the use of predictive, descriptive and interpretive models within the cenological paradigm.

2. To reveal the parameters of the structural elements of generations, the tasks of analysis and interpretation of digital social systems, which provide the possibility of their clustering.

3. To adapt the existing tools for identifying and describing the parameters of the structure of human capital at all levels of management on the basis of interdisciplinary integration within the cenological paradigm.

4. To justify the possibility of specific and rank-specific description of the parameters of human capital based on the synthesis of the cenological approach and interdisciplinary methodology. It is necessary to develop tools for predicting their dynamics in the digital space.

5. To form a conceptual model for interpreting the results of the analysis of complex socio-economic processes and systems, enshrined in a new research paradigm, which involves not only a methodological synthesis of the research, but also further verification of the results.

6. To identify the axiological aspect of the application of species analysis within the framework of a new paradigm for studying complex socio-economic systems that can carry out statistical processing of new and traditional data, endogenous explanatory variables, unobservable limitations and systematic deviations in the results that characterize the formal presentation of the development processes of a modern society and economy. 


\section{Research methodology}

Scientific research in the field of structuring human capital from the standpoint of macroeconomics is presented from two points of view. On the one hand, the key parameters for the management of the state's human capital are investigated and formalized, on the other hand, forecasts are made for the development of the human capital model of the future. The authors of the article also investigated the problem from the standpoint of the scientific substantiation of complex systems as socio-economic cenoses representing a special kind of reality.

To implement and achieve the goal of the study, it is necessary to conduct a structuralspecific analysis of the category of human capital, including a stagewise consideration from three positions [5]:

1. Human capital is considered as a set of specific abilities available to an individual, which are supposed to be rationally used in the process of productive labor, these are:

- cognitive abilities (knowledge);

- practical experience (skills), talent, internal motives and incentives;

- physical strength (energy).

2. Human capital is regarded as a set of innate and acquired abilities of an individual. Their rational use in a professional environment will contribute to the growth of the domestic national product and lead to an increase in the well-being of the individual himself. The following categories will be added to the previous ones:

- education;

- moral values.

3. Human capital is understood as the main tool for the development of socio-economic systems, through investments in which a new type of economic relations is formed - an innovative economy. In this case, the leading position is occupied by the cognitive abilities of the individual. Human capital is viewed through the prism of the amount of expected discounts. Here, to the above categorical aggregates, such strata are added as:

- investments;

- property of accumulation;

- possessions;

- objects of intellectual property.

In addition to the presented structural and specific positions, the group of authors proposes to consider the stratification of human capital from the geopolitical positions of aggregation, depending on the level of economic coverage [6]:

- micro-level - at this level, human capital is considered and weighed from the point of view of the person himself, his family and organization. Here, capital is expressed in genetic characteristics and the qualities of an individual acquired during the period of labor activity, determines the interdependence of income and expenses, savings of a person and his family;

- meso-level - at this level, human capital is considered and weighed at the level of the region and industry, while the regional level is based on the totality of human capital of families, and the sectoral level is based on the totality of human capital of business entities. This capital acts as a means of maintaining the stability and development of the region and the industry at the level of federal districts;

- macro-level - at this level, human capital is considered as national human capital and is weighed at the state level and represents the accumulated costs of general education, health care, labor movement [7];

- mega-level - at this level, human capital is viewed as a global human capital and is weighed at the level of the commonwealth of states, continents and the entire world economy.

The accumulated experience in the field of stratification of human capital made it possible to identify its specific features, which were studied from the point of view of the individual: 
- the capital of health, manifested in the physical ability to work;

- cultural capital, it reflects intellectual and cultural characteristics;

- the capital of education, that shows the level of professional competence and qualifications of an individual, the ability for self-improvement;

- biological capital, it reflects the natural abilities and level of health of the individual;

- psychological capital, that shows the ability of an individual to perceive innovations, his sociability in the process of life.

Thus, a hypothesis is being developed that modern social structures are distinguished by the complexity of formation and they organize complex systems. Their study requires an integrated interdisciplinary approach. The central problem of the new image of the concept of human capital is its assessment [11]. Scientific synthesis based on sociocenosis will allow to reveal the complex-structured properties of communities localized in the framework of time and space as a single whole, which can be observed, statistically determined and articulated into other interdependent and complementary connections.

\section{Foundation and semiotics of social cenosis}

Cenology is the science of the sustainability of large systems. In its structure, large complex systems are called cenoses, which are formed from a unique community of mutually related elements endowed with individual properties. There are various types of cenoses, the most famous are bio- and technocenoses. In the social sphere, "elements" are people, organized social groups of people (entrepreneurs, labor collectives, parties, study groups), as well as social systems (institutions). Thus, sociocenosis is a set of social elements that form a rank distribution in the statistical evaluation of key parameters (see Fig. 1).

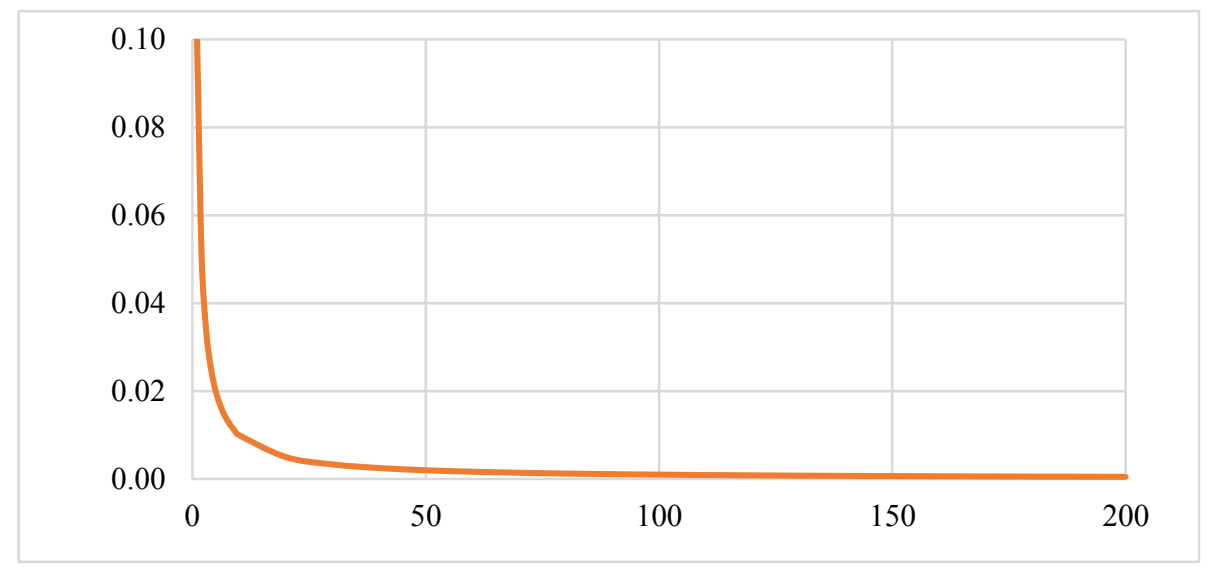

Fig. 1. Extremely skewed distribution (hyperbolic H-distribution).

The types of social cenosis are distributed along the axis of arguments, and the number of elements of this type is distributed along the axis of the function. This hyperbole reflects a stable pattern of communities of this type, described by the formula (1):

$$
W=A / \mathrm{r}^{\beta}
$$

where $\mathrm{A}$ is the maximum value of the parameter of the cenosis element with rank 1 , i.e. at the first point (or approximation coefficient); $r-a$ rank number; $\beta$ is a rank coefficient characterizing the degree of steepness of the distribution curve (moreover, mathematicians have determined that the best state of the cenosis is finding the parameter in the range of 0.5 $\leq \beta \leq 2.0$ ). The curve shown in Figure 1 is called the hyperbolic H-distribution and reflects the basic cenological law on the obligatory nature of this form for such systems. 
Some research groups [12] have implemented the research in the field of interdisciplinary modeling of the structure of human capital using data obtained by the Big Data analytics method. Distributions of a hyperbolic type are known in sociology and psychology. As an example (see Fig. 2), a graph of the distribution of the cenosis of "Russian universities" by the indicator "the number of the reduced contingent" and its approximation (dashed line on the graph) is presented.

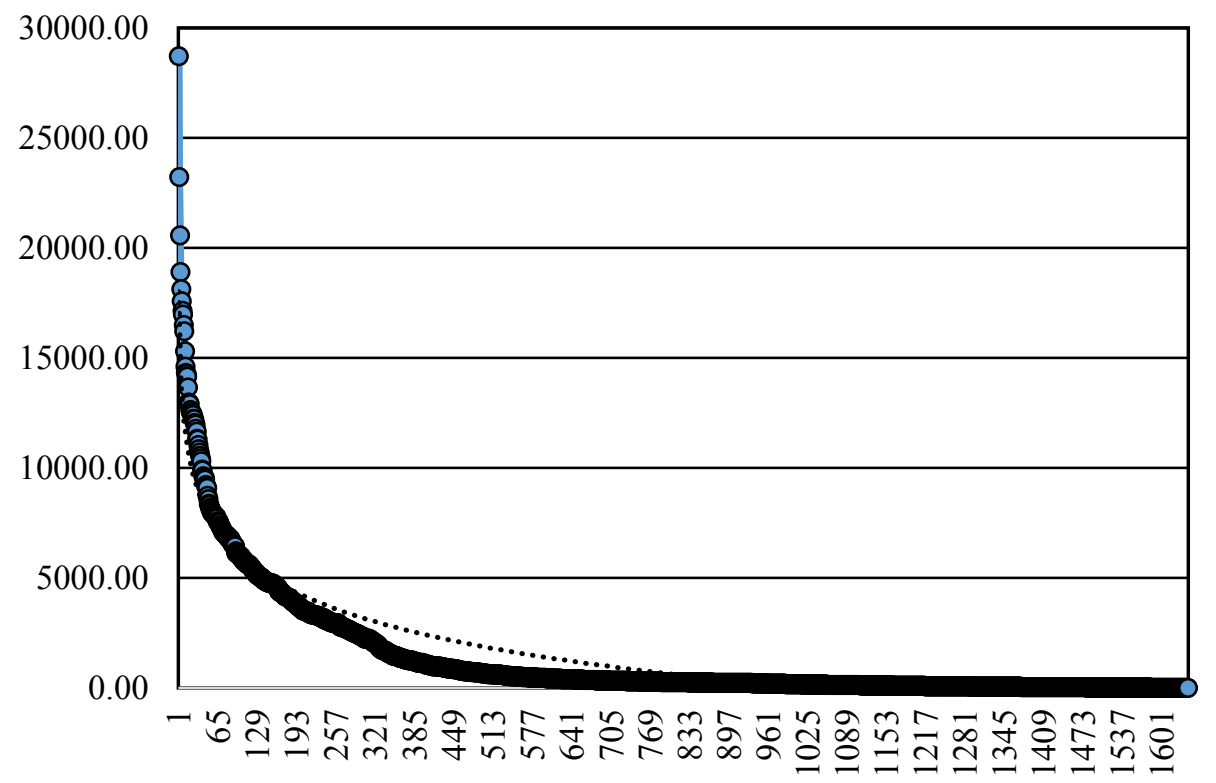

Fig. 2. Ranking distribution of Russian universities according to the indicator "the number of the reduced contingent" [13].

The graph shows that a significant part of the entire contingent is concentrated in a small part of the university system. Half of the contingent is concentrated in $10 \%$ of the country's universities, due to which there is a decline in the number in other universities. This cenosis is unstable.

The nature of the formation of the structure and patterns of cenoses is due to the competition of elements-universities for a limited resource (in this case, applicants), where the possession of a resource seems extremely probable. Cenoses have the character of a discrete distribution, i.e. with the help of cenological analysis, it is possible to study the system as a whole and the conditions under which this system is stable.

Let us consider in more detail human capital as a parameter of the cenological analysis. The modern element of sociocenosis (a person) has a variety of skills and abilities, for example, has an engineering education, knows one or several programming languages, is interested in certain creativity, owns property, speaks several languages. In retrospect, a person did not have many skills and abilities, and the further back, the less the accumulated intellectual (human) capital. These skills and abilities represent a complex cenological system with loosely-coupled elements.

They will have a huge effect on society (the population) and the person (the element) personally if used wisely. In order to determine the value of human capital, its structure must be stratified. The main thing is to understand how effective it is, how stable it is, whether there are "extra" competencies or some lack of it. There are qualitative and quantitative connections between all elements, which are not arbitrary, but natural. It does not matter what 
parameter of human capital is present in a person, the ratio of the types of these parameters is important [14].

There are difficulties in identifying the cenosis, its structure, and key parameters. These procedures require serious preliminary professional work, including the use of modern machine learning technologies, cognitive and semantic analysis. Together, they will make it possible to determine a list of all probable values and parameters of the considered cenosis, but one thing remains unchanged: the tendency of the distribution to a hyperbolic form.

Sociocenoses are of three types:

1. Static cenosis - the number of elements and species is invariable and does not depend on the moment of their calculation. All kindergartens in the region are an example of a static cenosis. Static cenoses are predictable, therefore they can serve as a standard for measuring other types of cenoses.

2. Equilibrium cenosis - the number of species is constant, but the number of elements changes. An example of an equilibrium cenosis is the interdependent numerical ranking "employed-unemployed". This dynamic equilibrium can exist indefinitely, provided there is no external influence. The stability of equilibrium cenoses is characterized by the stabilization of the number of cenosis elements within certain boundaries. By the form of the cenological hyperbole, it is possible to identify when this equilibrium is violated and the cenosis turns into a dynamic state. Deviations indicate a weakening or strengthening of bonds between elements.

3. Dynamic cenosis - the number of elements and species is variable. Most sociocenoses are just like that. Dynamic sociocenoses are stochastic in nature. The appearance of new species brings about the change (disappearance) of other species. Prediction of changes is possible only when analyzing similar (undergone changes) or reference cenoses.

As for the artificial formation of cenoses, it is necessary to ask the question why an order arises in large systems. The cenosis is formed by the idea (is programmed). The idea manifests itself, for example, in the policy of the state. Having set the task of solving the demographic problem, the state receives a new characteristic of human capital - "the presence of a large number of children" and its rating receives the maximum assessment in the species ranking. Based on the goals and objectives of the cenosis design, it seems possible to launch the processes of self-organization, point-wise affecting individual species (elements), artificially improving or worsening conditions for them, which will lead to the beginning of self-organization processes that ensure the stability of the cenosis.

To determine the stability of a socio-system of a cenological type, first, it is necessary to separate the system from the surrounding world; secondly, to characterize its functional purpose; thirdly, to predict its relationship with other (selected) objects in time. The cenosis is stable if the number of species in it is constant, but the number of elements changes.

Modern man has skills and knowledge that he does not always use. In a cenosis, the element that is not required by the functionality of the cenosis finds another application. This property fundamentally distinguishes cenological systems from Gaussian ones, which is confirmed by some studies [15]. The stability of cenoses is possible:

a) due to the ambiguity of the functions of each element;

b) due to the continuous variability of functional relationships between individuals.

There is no control center in the cenoses. Therefore, each element acts according to the setting. The cenosis will respond to any impact by changing the distribution of elements and directing them to a hyperbolic H-distribution: the cenological system finds an answer that may differ far from the expected one. Thus, with the help of the idea of sociocenoses, it becomes possible to construct reality in accordance with important target settings reflecting the development trend of the country, society, productive forces, allowing to take into account new parameters that characterize such objects today as human capital in all its diversity and rely on system-wide properties, including self-organization. 


\section{Discussion}

Today, it is urgent to construct digital reality, taking into account the targets aimed at raising the economy after the pandemic, which largely depends on the professional attitude to human capital as the basis and source of any social development. In this regard, the methodological techniques of the cenoses theory in conjunction with interdisciplinary research make it possible to design the state of generations according to the fundamental laws of its development.

An extensive analysis of already done scientific work aimed at studying human capital indicates that the understanding of many aspects of research is far from complete due to the lack of quality data and their intellectual analysis. Many models are focused on limited probabilistic samples, generally recognized analysis tools have not been developed, the negative social nature of the procedures for the classical metrification of human capital in the long term is noted.

All the studies carried out boil down to the point of view that cenosis management means minimal impact. This is control at the level of changing the ideas that form the cenosis. In an effort to achieve an H-distribution, he redistributes the ratio of elements in accordance with the new idea. Human capital as a cenosis is capable of performing many functions. Its stability is manifested through the law of the hyperbolic H-distribution. This advantage it will give an opportunity to create a purposeful structure of human capital, allowing to construct a key social image of a generation.

In further studies, the authors intend to propose a technology for the species clustering of complex social systems of the cenotic type in the parameters characterizing the current state of the structure of human capital, which allows for targeted state influence in order to form optimal invariants for the construction of social systems that ensure sustainable development on the basis of new automatic start of self-organization processes.

\section{Conclusions}

The use of cenoses will make it possible to form a new unique theoretical and methodological approach to modeling and managing social systems in the digital space. It will contribute to the sustainable development of the state, determine the place of a person in the new informational stratification of society. The use of cenoses will give a perception of the digital future of Russia by various social groups, including:

- the formation of a new terminological and semantic apparatus for representing complex social systems using structural-dynamic, cenological and cognitive approaches. The resulting synthetic classification of terms and provisions will provide a new quality of reevaluation of the hierarchy of scientific concepts and relationships of research objects;

- theoretical substantiation of the cenological paradigm for modeling the structure of generations in the information space, supplemented by interpretive and cognitive representations within the framework of the epistemological approach;

- interdisciplinary integration of cognitive models, statistical and cenological tools for researching generations in the information space;

- empirical testing of the formulated hypotheses based on data characterizing the state of human capital in order to identify general patterns and further algorithmic procedures;

- basic principles of a recommendation system for the formation of a targeted structure of human capital based on the technology of species analysis. A species is understood as a stable set of generations - carriers of a certain set of parameters of human capital;

- qualitatively new ideas about the nature of complex social systems, patterns of structural transformation, their classification and interpretation according to new qualitative features. 


\section{References}

1. Kuz'minov, A.N., Djukha, V.M., Chefranov, S.G. et al.: Interdisciplinary foundations for the research of large-scale economic systems based on the theory of cenoses (Publishing and printing complex of the Rostov State Economic University, Rostov-onDon, 2018)

2. Notsu, A., Yasuda, K., Ubukata, S., Honda, K.: Applied Soft Computing 97(B), 106723 (2020). https://doi.org/10.1016/j.asoc.2020.106723.

3. Agüero, J.M., Balcázar, C.F., Maldonado, S., Ñopo, H.: Journal of Development Economics 148, 102581 (2020). https://doi.org/10.1016/j.jdeveco.2020.102581.

4. Dorofeev, A.F.: Bulletin of the Kursk State Agricultural Academy 1, 76-80 (2018) http://www.journal-kgsha.ru/data/documents/2018-01.pdf

5. Voronina, A.V., Okhotnikov, A.V. Competence-based approach to transforming the content of the labor potential of the organization's personnel. Kant 1(18), 91-98 (2016) https://doi.org/10.24923/2222-243X-2016-18-1.

6. Zabelina, O.V., Kozlova, T.M., Romanyuk, A.V.: Statistics and Economics 4, 52-57 (2013) https://doi.org/10.21686/2500-3925-2013-4-52-57.

7. Kurganskiy, S.A.: Bulletin of the Baikal State University 6(80), 15-22 (2011) http://izvestia.bgu.ru/reader/article.aspx?id=14572.

8. Perez-Alvarez, M., Strulik, H.: Journal of Economic Behavior \& Organization 181, $211-$ 240 (2020) https://doi.org/10.1016/j.jebo.2020.11.034.

9. Liu, Sh., Yang, X. Regional Science and Urban Economics 87, 103620 (2020) https://doi.org/10.1016/j.regsciurbeco.2020.103620

10. Doppelt, R.: Review of Economic Dynamics 31, 84-122 (2019) https://doi.org/10.1016/j.red.2018.12.004.

11. Hatuka, T., Zur, H., Mendoza, J.A.: Cities 111, 102978 (2021) https://doi.org/10.1016/j.cities.2020.102978.

12. Ketova, K.V., Romanovsky, Y.M., Rusyak, I.G.: Computer Research and Modeling 11(2), 329-342 (2019)- https://doi.org/10.20537/2076-7633-2019-11-2-329-342

13. Kuz'minov, A.N., Kuizheva, S.K.: Scientific journal of the Kuban State Agricultural University 7(121), 1081-1097 (2016) https://doi.org/10.21515/1990-4665-121-067

14. Abazieva, K.G., Voronina, A.V., Goncharova, S.N.: Science and education: economy and economics; entrepreneurship; law and administration 4(107), 36-39 (2019) https://www.elibrary.ru/download/elibrary_37329060_53337991.pdf

15. Poelmans, J., Ignatov, D.I., Kuznetsov, S.O., Dedene, G.: International Journal of General Systems 2(43), 105-134 (2014) https://doi.org/10.1080/03081079.2013.862377 